\title{
HYPOTHESISED AND ACTUAL CHANGES IN THE GENERAL MOTOR PARAMETERS OF FIELD HOCKEY PLAYERS DURING THE TRAINING CYCLE
}

\author{
RYSZARD STRZELCZYKIA, JAN M. KONARSKIㄹ, KRZYSZTOF KARPOWICZ1A, JAROSŁAW \\ JANOWSKIIA, SYLWIA BARTKOWIAKIA, AGATA KONARSKA², TOMASZ PODGÓRSKIB \\ 1Poznan University of Physical Education, Faculty of Physical Education, Sport and Rehabilitation, \\ Department of Theory of Sport ${ }^{a}$, Department of Biochemistry ${ }^{b}$, Poznań, Poland \\ 2Stanisław Staszic University of Applied Science in Piła, Institute of Health Care, \\ Department of Physiotherapy, Piła, Poland
}

\begin{abstract}
Mailing address: Jan M. Konarski, Poznan University of Physical Education, Department of Theory of Sport, 27/39 Królowej Jadwigi Street, 61-871 Poznań, tel./fax: +48 61 8355260, e-mail: konarski@awf.poznan.pl
\end{abstract}

\begin{abstract}
Introduction. The aim of the study was to determine the changes in selected motor parameters of highly skilled field hockey players during the training macrocycle. It was assumed that the changes in the parameters examined in the study would correspond with the hypothesised variation related to the adaptive changes that were expected to take place. Material and methods. The study involved eleven field hockey players from the KS AZS-AWF Poznań club (age $=22.3 \pm 1.1$ years; height $=176.5 \pm 4.0 \mathrm{~cm}$; weight $=75.2 \pm 6.3 \mathrm{~kg} ; \% \mathrm{FM}=12.2 \pm 3.9 \% ; \mathrm{VO}_{2} \mathrm{max}=55.4 \pm 4.85 \mathrm{ml} / \mathrm{kg} / \mathrm{min}$ ). The dates of the measurements were agreed on with the trainers, who played an active role in the study, and were consistent with the cycle of planned measurements that were aimed at assessing the implementation of training/competition loads (two measurements during the preparatory period and one during the competition period). We examined the fundamental elements of motor preparation that are considered important in field hockey, that is speed endurance, running speed, and aerobic endurance. These assessments were supplemented by the measurements of lactate concentration in capillary blood as well as those of jumping ability and agility. Results. In most cases, the changes in the actual results corresponded with the hypothesised values adopted for the training. The relationships between the levels of particular parameters of the players' motor skills were adequate to a great extent. Conclusion. The effects of the training observed both for the entire team and for individual players were generally in line with the goals of the training/ competition loads implemented. Any discrepancies that were found were identified and corrected by regulating individual exercise loads and were monitored in subsequent measurements.
\end{abstract}

Key words: team games, optimisation, relativization, practical applications

\section{Introduction}

Modern sports training requires the continuous collection and processing of data concerning the individual reactions of players to the training loads implemented. Therefore, there is a need for interdisciplinary research that would examine the elements of internal reactions to external loads applied during training and competitions [1, 2].

Exercise evokes certain reactions in the body and induces numerous changes in several of its functions. These changes reflect the body's adaptation to the loads used. If the exercise is properly adjusted, it causes athletes' physical capacity to increase. Knowledge concerning this issue is gained by coaches in the process of monitoring the training, which is an important element of its optimisation. Training optimisation is based on a number of logically organised actions, including an analysis of players' performance during competitions and deliberate planning of the loads applied during particular parts of the training period, each part having a clear and legitimate goal. Optimisation should lead to gradually improving players' motor capacities in consecutive training cycles according to the goals set [3, $4,5,6]$. What is important in this respect is the choice as to what one should measure or estimate and how and the fact that this choice should be informed by practice.

Research has shown that the key capacities of field hockey players are speed endurance, speed, and aerobic endurance [7]. In order to prepare an adequate training programme, it is necessary to carry out an assessment of the initial level of primary motor capacities, which is then repeated at moments during the training cycle related to its periodisation and to the goals that are to be achieved with regard to the skills trained.

Research findings indicate that key motor capacities should be characterised by a certain degree of variation that can be predicted using a hypothetical model (Fig. 1) [4, 8]. The proposed model should be adjusted to the individual predispositions of a given player and the ability they make predominant use of (speed, endurance, or speed endurance), and it should also include other capacities or abilities which play a key role in the achievement of the training and competition goals set. This is illustrated in Figure 1, which depicts the model used in the study, where not only the key motor capacities are included, but the element of agility has been introduced as well, since agility may have a major influence on the performance of competitive tasks by players in different positions. 


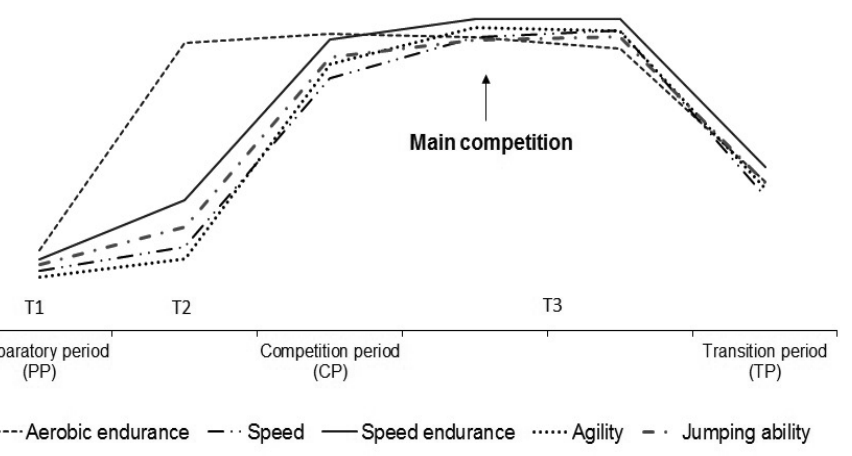

$\mathrm{Tl}$ - first measurement, beginning of the preparatory period; T2 - second measurement, end of the preparatory period, beginning of the competition period; T3 - third measurement, competition period.

Figure 1. Hypothesised variation in primary motor capacities of players of team sport games during the annual cycle

According to the model, we expected that in the first part of the preparatory period, there would be a clear increase in aerobic endurance up to a certain predetermined level; this level would need to be stabilised and maintained in the following parts of the macrocycle, as this parameter is a functional basis for aerobic capacity. This would make it possible to then improve speed and agility, which gradually start to be trained in the second part of the preparatory period and then continue to be trained so that the highest predetermined level can be reached in the pre-competition period and stabilised before the main competition of the season. Speed endurance, which depends on aerobic capacity and speed, is developed in a similar way to (maximal) speed [9]. It also worth noting the variations in jumping ability, which to a great degree supports the speed and agility elements of the training [7]. An important element of such a model is determining initial values, target values, and the dynamics of the changes in particular motor capacities. Optimisation is then based on an analysis of the relationship between these elements and the levels of actual changes, which make it possible to verify the hypothetical model adopted [8] based on a kinematic analysis of the performance of the players during the matches $[10,11$, $12,13,14]$.

There is a dearth of analyses which emphasise the necessity to base training methods on hypothetical models informed by practice, particularly when it comes to teams such as training league teams and university teams. A detailed review of research in the field has been made by Podgórski and Pawlak [15].

The aim of our study is to determine changes in selected motor parameters in highly skilled field hockey players during the training macrocycle. It was expected that the variation in the parameters examined would correspond with the hypothesised variation, which was based on the adaptive changes predicted.

\section{Material and methods}

\section{Research participants}

The participants were 11 field hockey players from the KS AZS-AWF Poznań club. Their general characteristics were as follows $(\mathrm{M} \pm \mathrm{SD})$ : age $=22.3 \pm 1.1$ years, height $=176.5 \pm 4.0 \mathrm{~cm}$, weight $=75.2 \pm 6.3 \mathrm{~kg}, \% \mathrm{FM}=12.2 \pm 3.9 \%$, and $\mathrm{VO}_{2} \max =55.4 \pm$ $4.85 \mathrm{ml} / \mathrm{kg} / \mathrm{min}$.

\section{Procedure}

The tests were performed by a research group at the Department of Sport Theory of the Poznan University of Physical Education in cooperation with the KS AZS-AWF club in Poznań. All of the players and trainers were informed about the nature and procedures of the tests and agreed to participate. The research was approved by the Bioethics Committee at the Poznan University of Medical Sciences.

The tests were carried out in the same conditions and order during every measurement. The first measurement (Tl) was conducted at the beginning of the preparatory period, the second measurement (T2) was performed at the end of the preparatory period, and the third measurement (T3) took place in the second phase of the competition period. The main goal set for the team in terms of competitive performance in the cycle investigated was to take $1^{\text {st_-3rd }}$ place in the Polish field hockey first league.

The diagnostic value of the tests used in the current study was verified in earlier publications $[4,7,16,17,18]$.

The measurements were performed in the following order: anthropometric measurements of height, weight, and body composition, made using Tanita BC-418 (Japan) [19, 20], followed by measurements of motor capacities (speed, jumping ability, agility, aerobic endurance, and speed endurance).

Maximal speed was assessed in a test where the subject covered a distance of $20 \mathrm{~m}$; the measurement included a run-up of $0.5 \mathrm{~m}$ [16]. Time was measured with an accuracy of $0.001 \mathrm{~s}$ using a photocell system (Witty, Microgate, Italy). The participants used a standing start. The run was performed twice. The score that was better was considered in the analysis, and for statistical purposes, speed per second was calculated [m/s]. It was assumed that the subjects would achieve values of $6.97[\mathrm{~m} / \mathrm{s}]$ (i.e., $2.870 \mathrm{~s}$ ) [9].

Jumping ability was assessed using the vertical jump [cm]. The subject stood with one side against a centimetre measuring board and reached the highest point possible with a straight arm. Then, they performed a half-squat with the trunk bent forward, made an upward jump with vigorous bilateral take-off, and touched the board at the highest point of the jump. We calculated the difference between the height of the jump and the standing reach height, with an accuracy of $1.0 \mathrm{~cm}$. The subject performed 3 consecutive jumps, and the best score was considered in the analysis. A referential value of $60 \mathrm{~cm}$ was adopted [7].

Agility was measured using a figure-of-eight running test (s). The subject stood at the starting line in the middle distance between two 1.2-metre-heigh bars. The distance between the bars was $5 \mathrm{~m}$. The exercise consisted in making three figureeight-shaped laps as fast as possible, navigating around the bars. Time was measured with an accuracy of $0.01 \mathrm{~s}$. The target value adopted was a speed of $11.50 \mathrm{~s}$ [9].

Aerobic endurance was assessed using a 5-minute step test $[16,21]$. The subject stepped onto two steps of a height of $22.9 \mathrm{~cm}$ each, performing 30 steps per minute over a time of 5 minutes. After the completion of the test and a rest break lasting $60 \mathrm{~s}$, we recorded the pulse in a sitting position at 30-s intervals with 30 -s breaks - at $1 \mathrm{~min}$ to $1 \mathrm{~min} 30 \mathrm{~s}\left(\mathrm{a}_{1}\right), 2 \mathrm{~min}$ to $2 \mathrm{~min} 30 \mathrm{~s}\left(\mathrm{a}_{2}\right)$, and 3 min to 3 min $30 s\left(a_{3}\right)$ - using a Polar Team2 Pro system (Finland). The results of the measurement were expressed in the form of the efficiency index (EI), which was calculated according to the following formula:

$\mathrm{EI}=300($ exercise time in s) $\mathrm{x} 100 / 2 \times(\mathrm{al}+\mathrm{a} 2+\mathrm{a} 3)[\mathrm{pts}]$. 
It was assumed that the target value for this group was 100 points and more [8]. Before and after the test, a capillary blood sample was taken in order to measure blood lactate concentration (La).

Speed endurance was assessed using a 10 x 20 m repeated running test. After a 10-minute rest break following the step test, the players underwent the speed endurance test in groups of four. The test consisted covering a 20-m distance 10 times with the aim of developing as high speed as possible during each lap - with fatigue gradually increasing - with a 30-s break between consecutive repetitions of the run [22, 23, 24, 25]. Time was measured using a photocell system (Witty, Microgate, Italy), as was the case with running speed. It was assumed that the subjects would achieve values of 6.78 [m/s] (i.e., $2.950 \mathrm{~s}$ ) [8]. After this test, another blood sample was taken in order to measure lactate concentration.

Post-exercise heart rate (pulse) was measured using a Polar Team2 Pro system (Finland) so as to examine internal body reactions to the exercise. Heart rate data were used, among others, in determining individual loads and calculating the efficiency index after the step test [8].

Lactate concentration, a parameter indicating the level of the adaptation of the body to aerobic and mixed (aerobicanaerobic) exercise, was assessed based on measurements of the concentration of lactate in capillary blood. Before the warmup, a blood sample was taken from the finger pad in order to measure resting lactate concentration (the referential value was a concentration of up to $2 \mathrm{mmol} / \mathrm{L}$ ). Subsequent samples were taken after the aerobic exercise (step test; La_El = lactate concentration after aerobic endurance test), the referential value being a concentration of 2 to $4 \mathrm{mmol} / \mathrm{L}$, and the anaerobic lactic exercise (10 x 20 m running test; La_SE = lactate concentration after aerobic-anaerobic speed endurance test), the referential value being 9 to $11 \mathrm{mmol} / \mathrm{L}$. The referential values given above were used as estimates, and actual values depended to a great extent on an individual's predispositions, engagement, current state of preparation, disposition on a given day, etc., which were taken into consideration when interpreting the results $[8,26$, 27]. Lactate concentration was measured using the enzymatic conversion of lactate to pyruvate, which involves lactate dehydrogenase (LDH; EC 1.1.1.27) and NAD+. The conversion of $\mathrm{NAD}^{+}$into $\mathrm{NADH}^{+} \mathrm{H}^{+}$causes an increase in absorption at $\lambda=$
$340 \mathrm{~nm}$ proportionally to the lactate concentration [28]. Measurements were made using a multi-mode microplate reader (Synergy 2 SIAFRT, BioTek, USA).

\section{Statistical analysis}

The data were analysed using standard statistical methods. Normality of data distribution for particular variables was tested using the Shapiro-Wilk test. The results were presented in the form of mean values $(\mathrm{M}) \pm$ standard deviation values (SD). Differences between the values obtained in particular measurements were analysed using ANOVA and post-hoc tests. Statistical significance was set at $\mathrm{p} \leq 0.05$. In order to compare the results obtained for the variables, the results were normalised to the means for all the measurements and the standard deviations. All statistical analyses were carried out using Statistica ver. 12.0 (StatSoft, Inc., USA) for Windows. The results were compiled in tables $(\mathrm{M} \pm \mathrm{SD})$ and illustrated using graphs showing normalised values. In the individual profiles, we demonstrated the variations between consecutive measurements for all the players and for extreme individual cases.

\section{Results}

The results obtained have made it possible to observe how individual and mean values of the parameters investigated changed according to the training goals set. The nature and level of the variation found for particular parameters largely corresponded with the training/competition loads implemented.

Table 1 shows the mean results obtained by the players who participated in the study together with information on the statistical significance of the differences found. The data are illustrated in detail in Figures 2-6.

An analysis of the data in Table 1 shows that significant changes were observed for agility, lactate concentration after the step test (aerobic exercise), and lactate concentration after the repeated running test (mixed, aerobic-anaerobic exercise). For the remaining variables, no significant differences were found between measurements.

It was, therefore, interesting to examine the relationships between the results obtained and the tasks implemented in particular training periods.

Table 1. Statistics for the variables examined in consecutive measurements

\begin{tabular}{|c|c|c|c|c|c|}
\hline Variable & $\mathrm{T1}$ & $\mathrm{T} 2$ & T3 & Mean T1-T3 & Significance \\
\hline Running speed [s] & $3.05 \pm 0.113$ & $3.01 \pm 0.100$ & $3.03 \pm 0.140$ & $3.03 \pm 0.115$ & \\
\hline Jumping ability [cm] & $59.0 \pm 5.44$ & $60.9 \pm 5.09$ & $61.4 \pm 6.72$ & $60.5 \pm 5.67$ & \\
\hline Agility [s] & $12.8 \pm 0.54$ & $13.3 \pm 0.33$ & $12.9 \pm 0.49$ & $13.0 \pm 0.49$ & ${ }^{*} \mathrm{~T} 1-\mathrm{T} 2$ \\
\hline El [pts] & $94.0 \pm 7.37$ & $98.0 \pm 11.70$ & $95.0 \pm 11.19$ & $95.0 \pm 10.00$ & \\
\hline La_El [mmol/L] & $6.5 \pm 2.09$ & $3.9 \pm 1.59$ & $5.7 \pm 1.74$ & $5.4 \pm 2.08$ & ${ }^{* *} \mathrm{~T} 1-\mathrm{T} 2$ \\
\hline Speed endurance [s] & $3.10 \pm 0.086$ & $3.11 \pm 0.099$ & $3.15 \pm 0.092$ & $3.12 \pm 0.093$ & \\
\hline La_SE [mmol/L] & $9.4 \pm 3.05$ & $5.4 \pm 2.08$ & $7.6 \pm 2.46$ & $7.5 \pm 3.04$ & ***T1-T2 \\
\hline
\end{tabular}

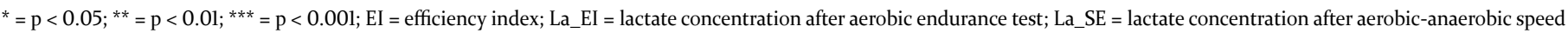
endurance test. 


\section{Speed}

The analysis of the data showed that the level of speed measured as a function of time changed, with an increase between the first and second measurements and then a minor decrease. The differences between particular measurements were not statistically significant, but a significant difference was found with respect to the hypothesised values. The results were below the expected values, and the shapes of the curves and the variations were different from the ones expected. The changes in the results are shown in Figure 2.

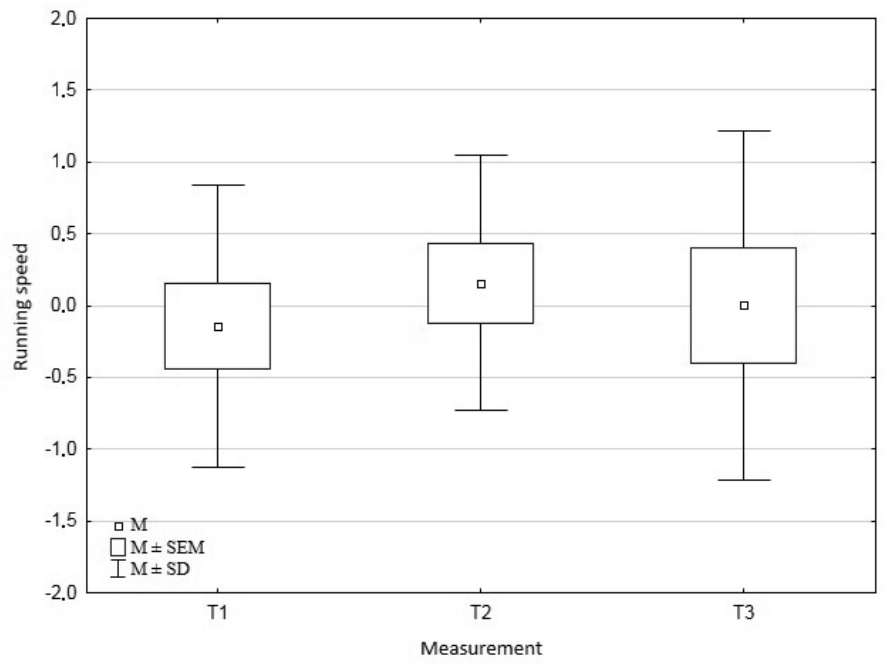

Figure 2. Normalised results of the speed test in consecutive measurements ( $10 \times 20$ m run)

\section{Jumping ability}

The results indicated that the players' jumping ability improved systematically in consecutive tests. An illustration of the results is shown in Figure 3.

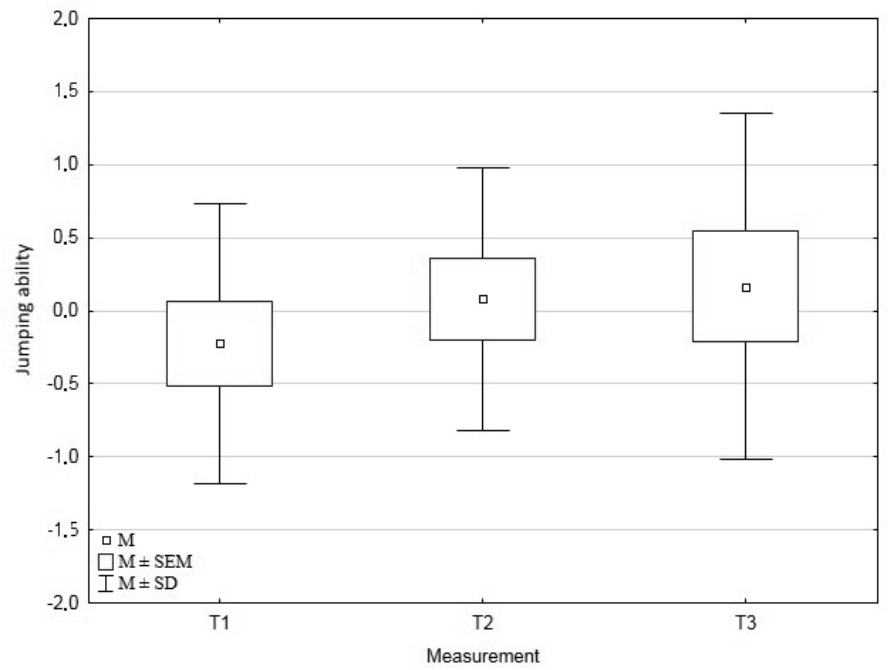

Figure 3. Normalised results of the jumping ability test in consecutive measurements (vertical jump)

\section{Agility}

The study found a statistically significant decrease in this ability between the first and second measurements, followed by a minor increase. The nature of the changes and the level of the ability observed did not correspond with our hypotheses. The results obtained with respect to this parameter are displayed in Figure 4.

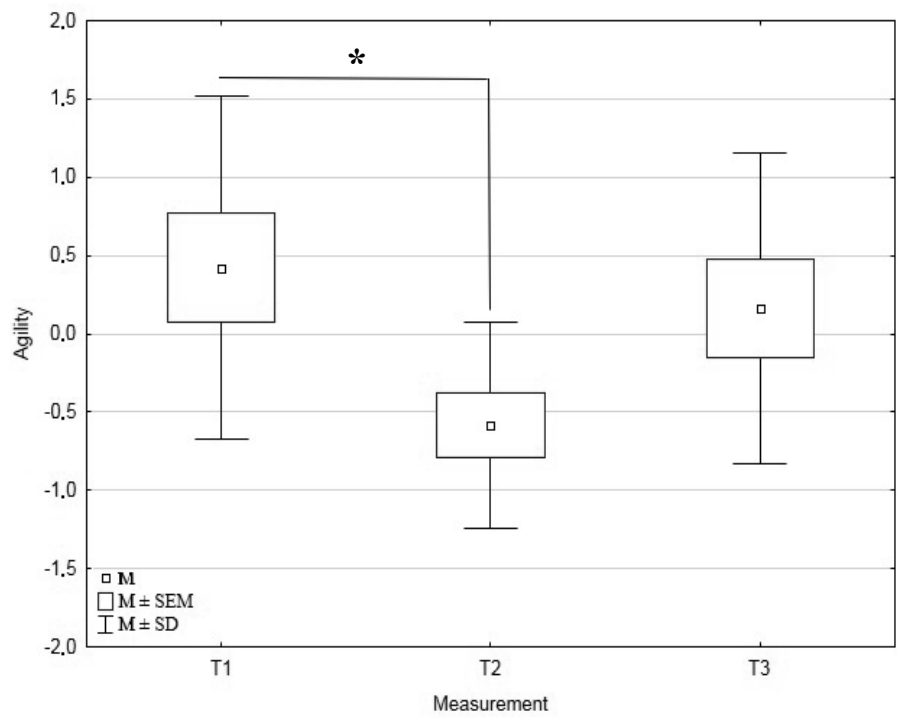

Figure 4. Normalised results of the agility test in consecutive measurements (figure-of-eight run) (statistically significant difference indicated with asterisk), ${ }^{*}=\mathrm{p}<0.05$

\section{Aerobic endurance}

The analysis of the results recorded for aerobic endurance performed based on the values of the efficiency index revealed that in all of the measurements, the players achieved results that were within the expected ranges. Although there were no statistically significant changes between consecutive measurements, the curves obtained for this parameter corresponded with those hypothesised. An increase in the values of this parameter was found between the first and second measurements, which was followed by a decrease stemming from a change in the training/ competition tasks performed (Fig. 5A).

As for blood lactate concentration, we noted a statistically significant decrease in the level of this parameter between the first and second measurements and then an insignificant increase (Fig. 5B, Tab. 1).

\section{Speed endurance}

The results of the speed endurance test which measured the main motor capacity in field hockey decreased in consecutive measurements. The differences between the measurements were not statistically significant, but the nature and level of the changes observed were not in line with our hypotheses, and, thus, this indicated an urgent need to verify the training/competition loads and the process of physical recovery (Fig. 6A). This is confirmed by the statistically significant decrease found for lactate concentration between the first and second measurements; its level then increased between the second and third measurements, though not significantly (Fig. 6B). Such changes might suggest that the players had low endurance potential; this is evidenced by the results of the aerobic endurance test, which changed in a similar manner (Tab. 1). 

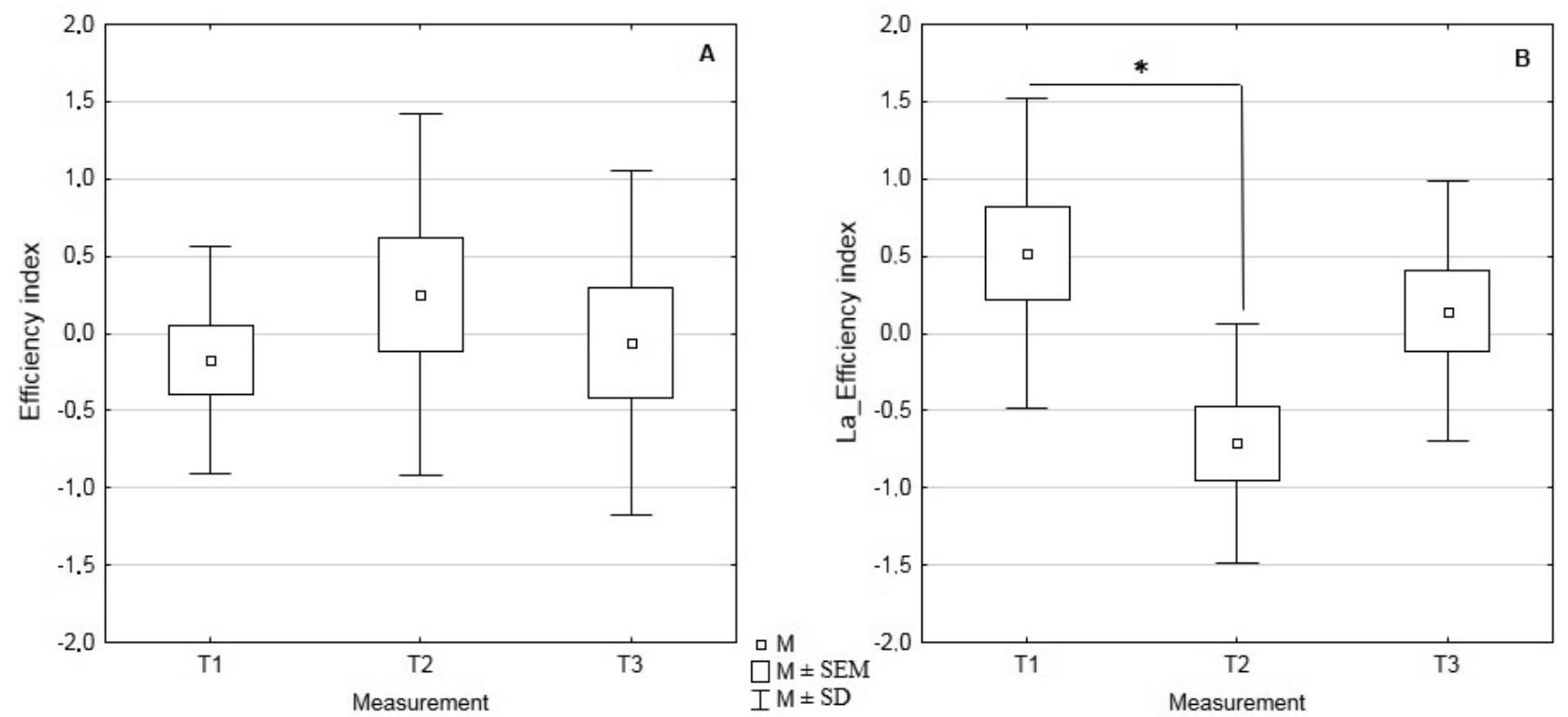

Figure 5. Normalised results for (A) the efficiency index (step test) and (B) lactate concentration after aerobic exercise in consecutive measurements (statistically significant difference indicated with asterisk), ${ }^{*}=\mathrm{p}<0.05$

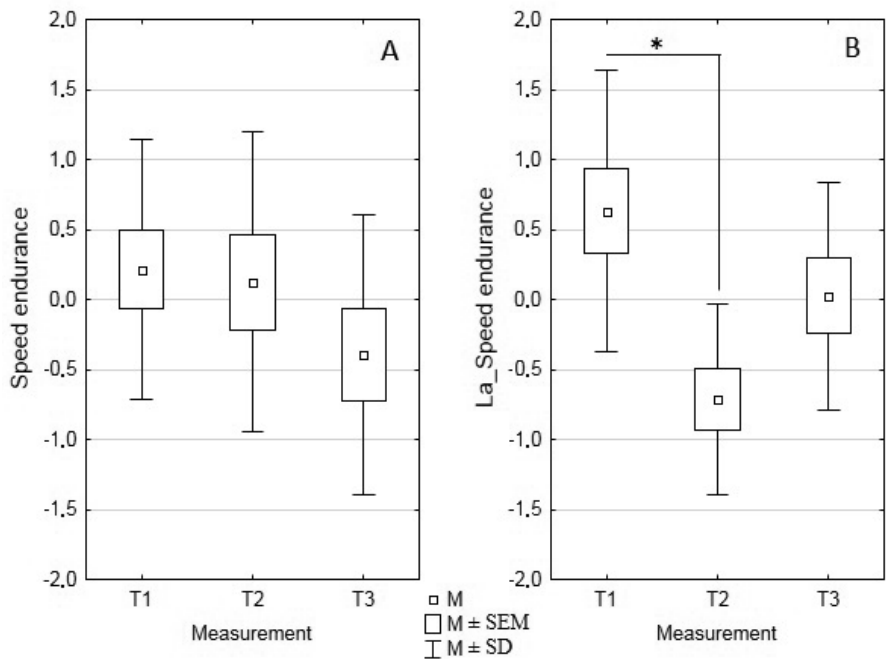

Figure 6. Normalised results of (A) the speed endurance test $(10 \times 20 \mathrm{~m}$ run) and (B) lactate concentration after aerobic-anaerobic exercise in consecutive measurements (statistically significant difference indicated with asterisk), ${ }^{*}=\mathrm{p}<0.05$

\section{Profiles}

If only the mean values obtained by the team were to be analysed, important information concerning individual players could be overlooked. One way of examining the results for particular subjects is normalising the results, investigating the changes in the profiles of the parameters examined for the entire team in consecutive measurements, and then analysing the performance of particular players with respect to the performance of the entire team. Thus, we normalised the values to the mean and the standard deviation, obtaining a zero value which was applied in all of the analyses. Next, we converted the results and arranged them so that higher values (also in the case of speed) were located in the outer parts of the graph.
When the profiles of all the players were analysed for the consecutive measurements, as illustrated in Figure 7, small variations could be observed for the elements examined. The parameters for which the greatest variation was observed were those for which statistically significant differences were found. In the competition period, the highest levels were recorded for jumping ability, which is indisputably an important element of the players' preparation with respect to the effectiveness of the tasks performed during the competition. This ability, however, should also be supported by the most important motor capaci-

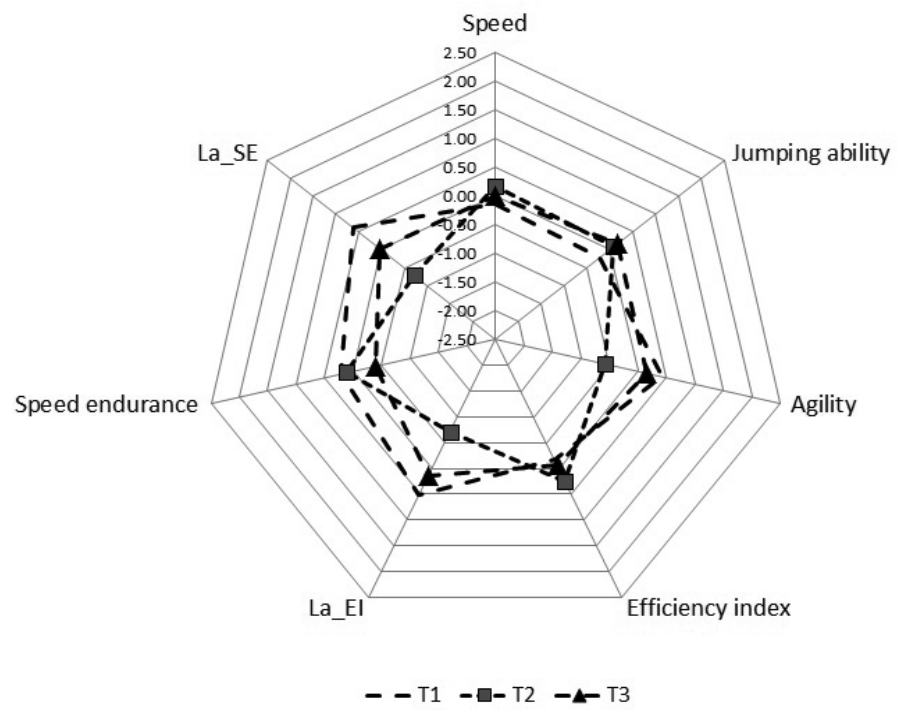

La_EI - lactate concentration after the step test; La_SE - lactate concentration after the $10 \times 20$ m running test.

Figure 7. Profiles of the changes in the parameters examined in consecutive measurements (normalised values) 


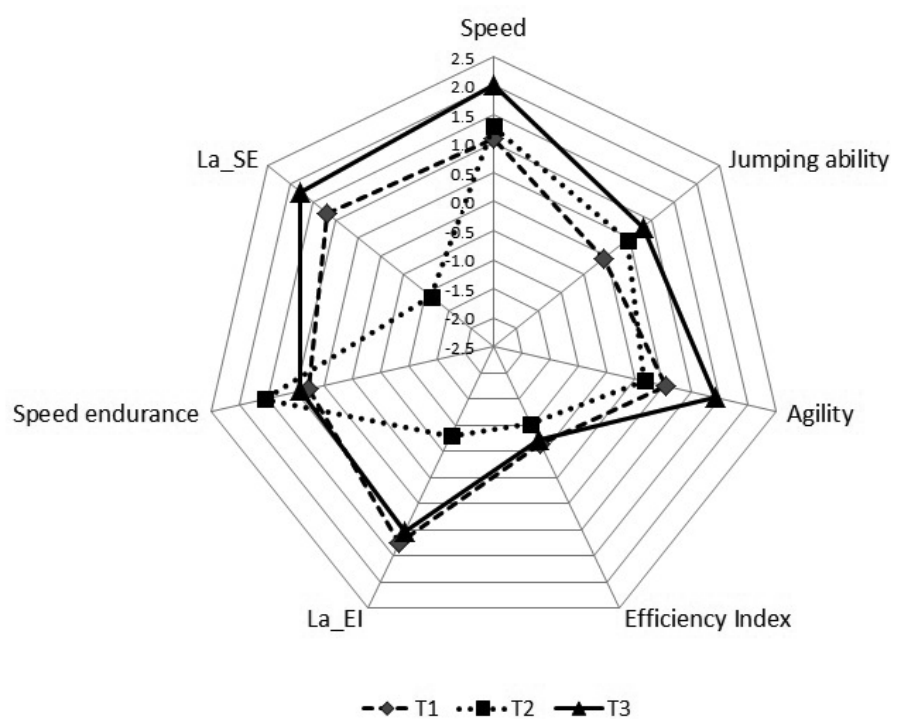

La_EI - lactate concentration after the step test; La_SE - lactate concentration after the $10 \times 20$ m running test.

Figure 8. Profile of subject Z2 whose results corresponded with the hypothetical model in consecutive measurements (normalised values)

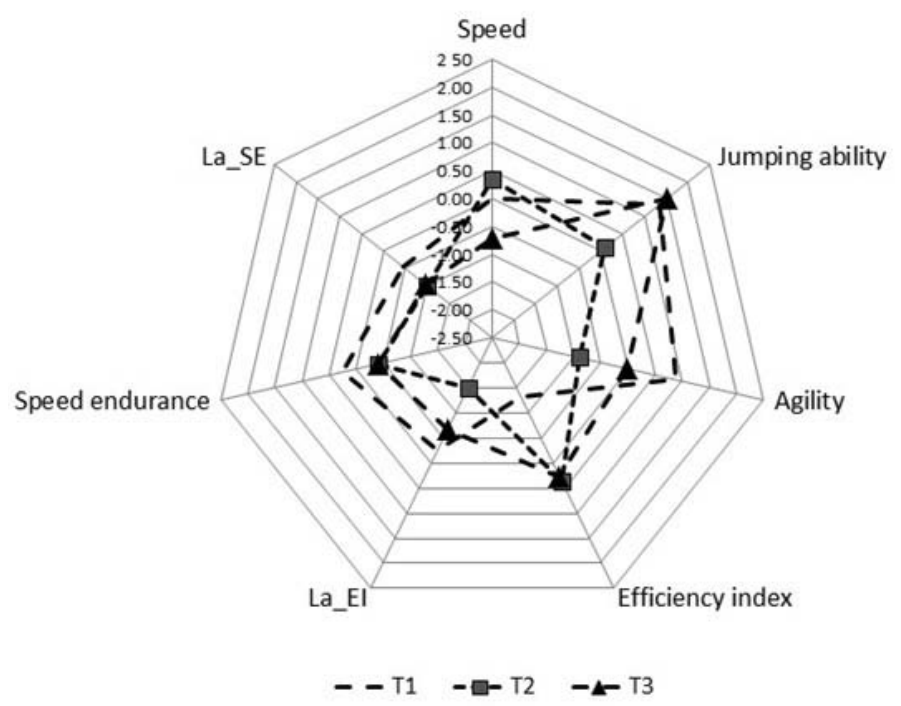

La_EI - lactate concentration after the step test; La_SE - lactate concentration after the $10 \times 20$ m running test.

Figure 9. Profile of subject Z6 whose results changes deviated from the hypothetical model in consecutive measurements (normalised values)

ties, whose level was not satisfactory with respect to the hypothesised values. There is also a possibility that speed skills were predominant in most of the athletes examined in the study. If this is in fact true, it is surprising that we found a low level of (maximal) running speed, which, similarly to jumping ability, reflects the players' predispositions for anaerobic work.

It is worth noting the individual profile of subject Z2 (Fig. $8)$; the changes in his parameters were in line with our hypothetical model. One should also pay attention to the third measurement, which is marked with triangles in Figure 8. In this measurement, this subject's results are considerably better than the mean for the entire group of players for most of the parameters examined in the study. It can be assumed that this subject is predisposed for anaerobic work, which is evidenced by the high levels of the anaerobic elements of the measurements and a low level of the efficiency index, measuring the capacity to perform aerobic work.

This can be contrasted with the results of subject Z6, whose results diverged considerably from the hypothesised changes in motor capacities during the training cycle (Fig. 9). The highest values in the third measurement were recorded for jumping ability and aerobic endurance. The subject achieved the highest values in speed endurance and agility in the first measurement. This suggests that there is a need to verify the training/competition loads used as well as to look at the consequences of the players' participation in matches during the indoor competition period, as they could have had a major influence on the levels of these motor capacities and impacted these levels during the outdoor competition period.

\section{Discussion}

Taking into consideration the constant increase in the level of the performance of players and teams, including in field hockey, there is a need to determine and modify the factors which are key in managing the training process effectively.

Based on a review of the literature and of our previous studies $[4,29,30]$, we assumed that the capacities that had a decisive influence of the effectiveness of performance in field hockey were speed endurance, understood as the capacity of the player's body to maintain a high level of sprinting ability despite increasing fatigue [31], and its two components. These components were aerobic endurance, which reflects the player's biological potential and is defined as the capacity to continue longlasting work with the required intensity without a decrease in the effectiveness of performance and with resilience to fatigue, and speed, understood as taking the shortest time possible required to cover a given distance or perform a given task under particular conditions $[17,18,32,33,34,35,36]$. What is required is the selection of adequate, reliable tests that are methodologically sound; the tests that were used in the current study were thoroughly examined in this respect earlier [21, 32, 37].

The optimisation model presented in the Introduction, according to which it was necessary to foster the development of the players' potential in an organised manner during the training cycle and compare actual values against expected values, showed that the player's results were the most similar to those hypothesised when it came to the running speed test, as these results gradually improved and were then maintained on a desirable level. The values recorded for speed endurance, on the other hand, decreased in the second measurement and then improved in the third measurement. It is difficult to state whether these changes were the result of an intervention by the coach or the effect of the players' participation in matches, which required the performance of tasks characterised by higher (anaerobic) intensity. Aerobic endurance decreased slightly in the second measurement (T2), as hypothesised. As far as agility (accuracy, speed) and jumping ability (strength, speed) are concerned, the values achieved indicated that these motor skills became better as the players started to take part in matches during the outdoor competition period. It should be stressed that these tests did not involve long-lasting effort, in contrast to the speed endurance test, whose results decreased slightly, with a simultaneous increase in lactate concentration. Similar findings were 
observed in the case of aerobic endurance; these were likely the symptoms of the fatigue that the players were experiencing.

The data collected both for individual players and for the entire group were instantly analysed in terms of the changes that could be observed. The results of these analyses were then used for the practical purpose of programming adequate individual modifications in the work loads, and this information was given to the coaches so that they could implement the modifications in subsequent training sessions.

The distribution of the results revealed differences between the expected values and actual values. This could have stemmed from issues in the implementation of the training or from the influence of factors unrelated to training, which were impossible to predict during training design when the relationship between the cause, that is the training load, and its effect were being considered. Ultimately, the assessment of the situation depends on the thoroughness of the analyses of the coaches and the players and on programming training/competition loads based on changes in training effects over time. What can be particularly helpful in selecting potential modifications is the accurate determination of values that are to be achieved at particular stages of the training and of expected changes in the levels of the functional parameters trained, with which actual effects will be confronted [8] (Fig. 1).

When planning training/competition loads, it is also significant to make sure that there is an adequate proportion between work and rest (supercompensation). Maintaining this proportion makes it possible to fulfil competition and training goals and, at the same time, prevent injury and overtraining [38, 39, $40,41,42]$.

The hypothetical model and the analysis of its implementation meet the above requirements and have allowed for the reliable assessment of the group of players examined and the selection of optimal training methods.

\section{Conclusions}

1. In most cases, the changes in the results corresponded with the hypothetical model formulated for the training. The relationships between the values indicating the levels of particular parameters of the players' motor and biochemical preparation were relatively adequate.

2. Using a combination of motor parameters (such as the $10 \mathrm{x}$ $20 \mathrm{~m}$ running test) and biochemical parameters (for example, blood lactate concentration), as described in the current article, has significant diagnostic and predictive value, since it allows for an accurate assessment of actual results in light of the hypothetical model adopted and the expected effects with respect to a player's performance during the match.

The above concluding remarks which stem from the procedure that was used to identify variation in the elements of motor preparation combined with the monitoring of changes in the internal reactions of the body can also be applied in other team game sports, particularly those where the game is played on large fields (soccer, ice hockey, American football, etc.).

\section{Acknowledgements}

The study was carried out under a scientific research grant awarded by the Polish Ministry of Science and Higher Education for the "Development of University Sport" (NRSA1002651, 2011-2014). We are grateful to the players and the coaches of KS AZS-AWF Poznan who participated in the research and to
Medkonsulting company for their technical support during the implementation of the grant.

\section{Literature}

1. Reilly T. (2005). An ergonomics model of the soccer training process. Journal of Sports Sciences 233(6), 561-572.

2. Reilly T. (2007). The science of training - soccer. London and New York: Routledge, Taylor \& Francis Group.

3. Strzelczyk R., Wachowski E., Konarski J., Janowski J., Karpowicz K., Wylegalski S. (1999). Hypothetical model of research effects after training in team games - guidelines model. Book of Abstracts, $6^{\text {th }}$ Sport Kinetics Conference' 99 , 1-4 September 1999 (p. 166). Ljubliana: University of Ljubliana.

4. Strzelczyk R., Konarski J., Karpowicz K., Janowski J. (2001). Changes in the main abilities of field hockey players during the preparatory period leading up to the main competition. Acta Gymnica 31, 17-21.

5. Ryguła I. (ed.) (2005). Elements of theory, methodology, diagnostics, and optimisation in sports training. Katowice: AWF Katowice. [in Polish]

6. Sharkey B., Gaskill S. (2006). Sport physiology for coaches. Champaign, IL: Human Kinetics.

7. Wachowski E., Strzelczyk R. (1991). Advantages of motor abilities. Trening 1(9), 106-114. [in Polish]

8. Konarski J., Krzykała M., Podgórski T., Pawlak M., Strzelczyk R., Malina R.M. (2012). Variation in functional and morphological characteristics of elite Polish field hockey players during a complete training cycle. International Journal of Sports Science and Coaching 7(3), 527-541.

9. Konarski J., Strzelczyk R., Karpowicz K., Janowski J. (2015). Theory of sport. In R. Strzelczyk, J. Konarski, T. Podgórski, M. Pawlak (eds), Field hockey. History, Theory, Methodology, Practice (pp. 232-288). Poznań: AWF Poznań. [in Polish]

10. Reilly T., Borrie A. (1992). Physiology applied to field hockey. Sports Medicine 14(1), 10-26.

11. Spencer M., Lawrence S., Rechichi C., Bishop D., Dawson B., Goodman C. (2004). Time-motion analysis of elite field hockey, with special reference to repeated-sprint activity. Journal of Sports Sciences 22, 843-50.

12. McManus A., Stevenson M., Finch C. (2005). Time-motion analysis: Non-elite field hockey. Journal of Science and Medicine in Sport 8(Suppl. 1), 68.

13. Konarski J. (2010). Characteristics of chosen parameters of external and internal loads in Eastern European high level field hockey players. Journal of Human Sport and Exercise 5(1), 43-58.

14. Konarski J. (2015). Measuring and analysing training/competition loads in field hockey. In R. Strzelczyk, J. Konarski, T. Podgórski, M. Pawlak (eds), Field hockey. History, Theory, Methodology, Practice (pp. 160-162). Poznań: AWF Poznań. [in Polish]

15. Podgórski T., Pawlak M. (2011). A half century of scientific research in field hockey. Human Movement 12(2), 108-123.

16. Wachowski E., Strzelczyk R., Osiński W. (1987). Measuring motor fitness skills in sport practitioners. Research results. Poznań: AWF Poznań. [in Polish]

17. Wachowski E., Strzelczyk R., Wylegalski S. (1999). Motor fitness norms for competitive soccer players. In A. Stuła (ed.), Modern soccer: Theory and practice (pp. 157-159). Gorzów Wielkopolski: IWF Gorzów Wlkp. [in Polish]

18. Strzelczyk R., Konarski J., Janowski J., Karpowicz K., Witczak K. (2003). Characteristics of variations in special 
physical fitness of field hockey players during training for the '99 European Championship in Padua. In R. Strzelczyk, K. Karpowicz (eds), Physical education and sport in scientific research (pp. 347-351). Poznań: AWF Poznań. [in Polish]

19. Malina R.M. (2007). Body composition in athletes: Assessment and estimated fatness. Clinics in Sports Medicine 26(1), 37-68.

20. Eston R., Reilly T. (2009). Kinanthropometry and exercise physiology laboratory manual. Tests, Procedures, Data. Volume 1: Anthropometry (3rd ed.). London and New York: Routledge, Taylor and Francis Group.

21. Strzelczyk R., Wachowski E., Banaszak F., Kerste M. (1993). Research on the internal validity of a battery of endurance tests, with special focus on the Master step test. Wychowanie Fizyczne i Sport 3, 17-29. [in Polish]

22. Wragg C.B., Maxwell N.S., Doust J.H. (2000). Evaluation of the reliability and validity of a soccer-specific field test of repeated sprint ability. European Journal of Applied Physiology 83(1), 77-83.

23. Aziz A.R., Chia M., The K.C. (2000). The relationship between maximal oxygen uptake and repeated sprint performance indices in field hockey and soccer players. Journal of Sports Medicine and Physical Fitness 40, 195-200.

24. Aziz A.R., Chuan T.K. (2004). Correlation between tests of running repeated sprint ability and anaerobic capacity by Wingate cycling in multi-sprint sports athletes. International Journal of Applied Sports Sciences 16(1), 14-22.

25. Wachowski E., Strzelczyk R., Janowski J., Wylegalski S. (1997). Motor indices of senior and junior football players' training with respect to sports competition requirements. In P. Blaster (ed.), Sport Kinetics '97. Theories of human motor performance and their reflections in practice, Vol. 2 (pp. 121-125). Magdeburg, Germany.

26. Astrand P.O., Hultman E., Juhlin-Dannfelt A., Reynolds G. (1986). Disposal of lactate during and after strenuous exercise in humans. Journal of Applied Physiology 61(1), 338-343.

27. Podgórski T., Pawlak M. (2015). Biochemistry. In R. Strzelczyk, J. Konarski, T. Podgórski, M. Pawlak (eds), Field hockey. History, Theory, Methodology, Practice (pp. 304-329). Poznań: AWF Poznań. [in Polish]

28. Maughan R.J. (1982). A simple, rapid method for the determination of glucose, lactate, pyruvate, alanine, 3-hydroxybutyrate and acetoacetate on a single 20 - $\mu$ l blood sample. Clinica Chimica Acta 122(2), 231-240.

29. Kowalski J., Strzelczyk R., Wachowski E. (1995). Research on speed endurance in team sports (based on field hockey) (pp. 31-35). Poznań: AWF Poznań. [in Polish]

30. Konarski J. (2013). Selected features determining elite performance in team sport games based on field hockey. Poznań: AWF Poznań. [in Polish]
31. Sozański H., Witczak T., Starzyński T. (1999). Fundametals of speed training. Warszawa: Biblioteka Trenera. [in Polish]

32. Wachowski E., Strzelczyk R., Dylewski T., Wylegalski S. (1995). Speed endurance in soccer. Trening 2, 33-46. [in Polish]

33. Kozłowski S., Nazar K. (1996). Introduction to clinical physiology. Warszawa: PZWL. [in Polish]

34. Strzelczyk R., Konarski J., Janowski J., Karpowicz K. (2015). Monitoring as a key aspect of training management. In R. Strzelczyk, J. Konarski, T. Podgórski, M. Pawlak (eds), History, Theory, Methodology, Practice (pp. 178-189). Poznań: AWF Poznań. [in Polish]

35. Sozański H., Czerwiński J., Sadowski J. (red.) (2013). Fundamentals of sports training theory and technology. Volume 1. Warszawa, Biała Podlaska: WWFiS in Biała Podlaska. [in Polish]

36. Sozański H., Czerwiński J., Sadowski J. (red.) (2015). Fundamentals of sports training theory and technology. Volume 2. Warszawa, Biała Podlaska: WWFiS in Biała Podlaska. [in Polish]

37. Wachowski E., Strzelczyk R. (1999). Accuracy of the measurement of motor condition features. Poznań: AWF Poznań. [in Polish]

38. Faliszewski S., Strzelczyk A., Konarski J. (2002). Preventing lower limb injuries in field hockey using isokinetic exercise - methodological solutions. In Sbornik referato ze 4. mezinarodniho vedeckeho seminare Efekty pohyboveho zatizeni $v$ edukacnim prostredi telesne vychovy a sportu (pp. 109116). Univerzita Palackeho v Olomouci. [in Polish]

39. Sherker S., Cassell E. (2002). A review of field hockey injuries and countermeasures for prevention. Report No. 143. Australia: Monash University Accident Research Centre. Retrieved January 25, 2012, from http://130.194.11.149/miri/ research/reports/muarcl43.pdf.

40. Konarska A., Konarski J. (2010). Incidence of injury in team sports, based on the example of field hockey. In M. Majchrzycki, D. Warzecha, P. Kocur (eds), Dysfunctions of the locomotor system. The role of osteopathy and manual therapy in the treatment of soft tissue (pp.146-157). Poznan: Wydawnictwo Naukowe Uniwersytetu Medycznego.

41. Bompa T.O., Haff G.G. (2009). Periodization: Theory and methodology of training. Champaign, IL: Human Kinetics.

42. Czubaszewski Ł., Konarska A. (2015). Motor rehabilitation. In R. Strzelczyk, J. Konarski, T. Podgórski, M. Pawlak (eds), History, theory, methodology, practice (pp. 436-454). Poznań: AWF Poznań. [in Polish]

Submitted: September 18, 2017

Accepted: November 7, 2017 